\title{
Educação Física em Moçambique: dilemas históricos da formação e atuação profissional
}

\author{
Physical Education in Mozambique: historical dilemmas of training and professional activity \\ Educación Física en Mozambique: dilemas históricos de la formación y actuación profesional \\ Pedro Antonio Pessula ${ }^{1}$; Madalena Tirano Bive ${ }^{2}$ \\ Universidade Pedagógica, UP, Maputo; Tete, MoçambiQue
}

\begin{abstract}
RESUMO
O presente artigo analisa o contexto histórico da formação e atuação profissional em Educação Física em Moçambique. Para a construção do mesmo foram consideradas as vivências e experiências dos autores como professores de Educação Física, artigos publicados e documentos oficiais. Constatamos que a formação de professores sofreu várias metamorfoses em função da realidade de cada época; desde o período colonial até hoje não houve mudanças em conteúdos lecionados na Educação Física escolar; a atuação profissional dos professores é influenciada pelos preconceitos e estereótipos de género e corpo onde se verifica a separação de meninos e meninas nas aulas e no tipo de atividade desportiva; há interferências das práticas sociais e culturais como os ritos de iniciação, os mitos e tabus nas aulas. Em função destas constatações, perspetivamos reconstruir a formação e a atuação profissional em Educação Física a partir de um olhar intercultural e pós- colonial.

Palavras-chave: Formação. Atuação Profissional. Educação Física. Moçambique.
\end{abstract}

\begin{abstract}
The present article analyzes the historical context of the formation and professional performance in Physical Education in the Mozambican context, taking into account the record shifts of the colonial period up to the moment. For the construction of the article, experiences of the authors as teachers of Physical Education, published articles and official documents were considered. We found that teacher training underwent several metamorphoses in function of the reality of each epoch; from the colonial period until today, there were no changes of contents taught in the Physical School Education; the professional performance of teachers is influenced by stereotypes of gender and body prejudices where it can be noticed the separation of boys and girls in the classes and in the type of sports activity to be performed in class in accordance with the body structure. There are negative influences of social and cultural practices such as initiation rites, myths and taboos in class. Based on these findings, we intend to reconstruct the formation and professional activity of the Physical Education teacher from an intercultural and postcolonial.
\end{abstract}

Keywords: Training. Professional Performance. Physical Education. Mozambique.

\section{RESUMEN}

El presente artículo analiza el contexto histórico de la formación y actuación profesional en Educación Física en el contexto mozambiqueño, teniendo en cuenta las transforaciones registradas del período colonial hasta el momento. Para la construcción del mismo fueron consideradas las vivencias y experiencias de los autores como profesores de Educación Física, artículos publicados y documentos oficiales. Constatamos que la formación de profesores sufrió varias cambio en función de la realidad de cada época; desde el período colonial hasta hoy no hubo cambios en contenidos leídos en la Educación Física escolar; la actuación profesional de los profesores es influenciada por los prejuicios y estereotipos de género y cuerpo donde se verifica la separación de niños y niñas en las clases y en el tipo de actividad deportiva a realizar en la clase en función del cuerpo; hay influencias negativas de las prácticas sociales y culturales como los ritos de iniciación, los mitos y tabúes en las clases. En función de estas constataciones, perspetivamos reconstruir la formación y la actuación profesional del profesor de Educación Física a partir de una mirada intercultural y postcolonial.

Palabras clave: Formación. Actuación Profesional. Educación Física. Mozambique.

\footnotetext{
${ }^{1}$ Docente da UP, Maputo. E-mail: pessula.fefd@gmail.com

${ }^{2}$ Docente da UP, Tete. E-mail: madalenatirano15@ gmail.com
} 


\section{INTRODUÇÃOO}

Moçambique é um país que se localiza na costa oriental da zona sul de África e foi colonizado por Portugal tendo alcançado a independência em 25 de junho de 1975.

Após a independência, o sistema de ensino esteve influenciado por medidas imediatas tomadas no sentido de retirar dos conteúdos programáticos escolares tudo que tinha a ver com a educação colonial como temas relacionados com a geografia, política e história de Portugal. Este sistema durou até 1983, quando foi elaborado o primeiro documento curricular moçambicano, a Lei 4/83 do Sistema Nacional da Educação (SNE), que estabelece em linhas gerais os fundamentos político-ideológicos, os princípios, as finalidades, os objetivos gerais e pedagógicos da educação em Moçambique (MOÇAMBIQUE, 1983).

O SNE instituía a educação como um direito e dever de todos os cidadãos e visava a formação do Homem Novo que devia ser dotado de mentalidade socialista e marxistaleninista. A escola deveria ser um espaço para o povo tomar o poder ao convidar todos para aderirem à democratização do ensino, fazendo do país, uma grande escola onde todos aprendem e todos ensinam (MOÇAMBIQUE, 1983).

Face as transformações sociais e econômicas que ocorreram nos princípios da década 1990, a Lei 4/83 foi revogada pela Lei 6/92 de 6 de maio (MOÇAMBIQUE, 1992). Neste contexto, os princípios gerais foram parcialmente reformulados passando a ser:

(i) Educação é um direito e dever de todos os cidadãos; (ii) o Estado, no quadro da lei, permite a participação de outras entidades, incluindo comunitárias, cooperativas, empresariais e privadas no processo educativo; (iii) O Estado organiza e promove o ensino, como parte integrante da ação educativa, nos termos definidos na Constituição da República; (v) O Ensino é público e laico (MOÇAMBIQUE, 1992, p.8).

A lei 6/92 foi acompanhada pela aprovação pelo Conselho de Ministro da Política Nacional da Educação da Resolução 8/95. Embora esta resolução assegure o acesso à educação a um número cada vez maior de pessoas e melhorar a qualidade dos serviços prestados a todos os níveis e tipos de ensino (MOÇAMBIQUE, 1995), nem sempre foi alcançado porque nem todos os cidadãos conseguem ter uma educação obrigatória de qualidade e acessível devido às imposições do mercado.

Segundo dados do último senso populacional em 2017, Moçambique é habitado por 28.861 .863 pessoas e apenas $26 \%$ da população moçambicana frequentam o ensino público e privado (INE, 2017).

É a partir desta realidade que pretendemos descrever os dilemas históricos da formação e atuação profissional em Educação Física em Moçambique. Para a construção do artigo tivemos como base de elaboração as vivências e experiências dos autores como professores de Educação Física, artigos publicados e documentos oficiais (leis, programas de ensino, planos curriculares e decretos) usados em Moçambique. Por conseguinte, optamos por uma pesquisa narrativa conjugada com a análise documental. As narrativas nos permitem analisar como nós, seres humanos, experimentamos o mundo. Dessa ideia geral se deriva a tese de que a educação é a construção e reconstrução de histórias pessoais e sociais; tanto dos/as professores/as como dos/as alunos/as que são contadores de histórias e também personagens nas histórias dos demais e nas suas próprias (CONNELLY; CLANDININ, 1990). A análise documental nos permitiu examinar os programas de ensino e os artigos publicados na temática de Educação Física em e sobre Moçambique. 


\section{FORMAÇÃo PROFISSIONAL EM EDUCAÇÃo FÍSICA E DESPORTO: PERSPECTIVA HISTÓRICA}

Em Moçambique, antes de 1969, não se realizava a formação de professores e técnicos de desporto. Por esta razão, através do Diploma Ministerial 1670 de 4 de maio de 1957 que aprova Regulamento Geral das Actividades Gimnodesportivas (CRISTÓVÃO, 2005), permitiu-se que a prática do desporto passasse de uma prática espontânea para legislada. Neste contexto, a falta de pessoal formado que se fazia sentir obrigou as autoridades, através do Conselho Provincial de Educação Física (CPEF), a rever o diploma.

Com a revisão do diploma em 1967, abriu-se espaço para o lançamento da proposta da criação junto à Universidade de Lourenço Marques (hoje chamada de Maputo, foi capital da Província Ultramarina de Moçambique), de uma Licenciatura em Treino Desportivo para a formação de Treinadores Licenciados em Desporto. Salientase, que esta proposta foi recusada pelo Ministério Ultramar. Em compensação, orientou a abertura da Escola de Instrutores de Educação Física de Lourenço Marques que iniciou suas atividades no ano de 1969 (CRISTÓVÃO, 2005).

Libombo $^{3}$, entrevistado por Muria (2009), afirma que o Professor Noronha Feio, então Presidente do CPEF, por reconhecer as potencialidades desportivas da colônia despoleta a necessidade de formação de professores de Educação Física. Devido aos elevados custos, falta de instalações e existência de poucos professores formados optouse pela Escola de Instrutores. O nível de ingresso era o quinto ano do liceu ${ }^{4}$ e o curso tinha a duração de dois anos. Depois de concluir o curso, os formados tinham que ter dois anos de prática para lhes serem conferido o título de bacharel, daí apenas ter que fazer mais dois anos em Portugal para se obter o título de licenciado.

Deste modo, a Escola de Instrutores de Educação Física de Lourenço Marques, criada em 1969, marca oficialmente, o início da formação dos professores de Educação Física e Desporto em Moçambique. Durante o período colonial, o curso formou cerca de 120 professores de Educação Física dos quais apenas doze permaneceram em Moçambique depois da independência (IMPULSO, 1987).

Ao mesmo tempo realizaram-se cursos de formação de monitores desportivos no período de 1967 a 1974 para trabalharem no Projeto do Caniço, em que milhares de praticantes na maioria da população nativa, do escalão etário dos 6 aos 12 anos estavam envolvidos na prática das modalidades de basquetebol, natação, ginástica, atletismo. Este projeto representou a massificação do desporto ao nível das zonas suburbanas como política de inclusão do regime colonial (MURIA, 2009).

Em 1975 é interrompida a formação de professores por falta de instrutores, porque os que existiam foram abandonando o país devido à conjuntura política que se vivia na altura com a nacionalização do ensino, saúde, habitação, entre outras áreas.

Portanto, podemos julgar que a formação de professores de Educação Física no período colonial era direcionada ao desenvolvimento desportivo e para difundir a ideologia do colonizador.

\section{FormaÇÃo de Professores de EduCAÇÃo FísiCA DEPOIS dA INDEPENDÊNCIA}

\footnotetext{
${ }^{3}$ Prof. Joel Libombo faz parte dos doze professores formados no período colonial em Educação Física que após a independência permaneceram no país e garantiram a formação e lecionação da disciplina após a saída de professores portugueses.

${ }^{4}$ Corresponde à $10^{\mathrm{a}}$ Classe do Novo Sistema de Educação de Moçambique.
} 
Após a independência, segundo Libombo em entrevista concedida a Muria (2009), houve abandono da maior parte dos professores com a saída maciça dos portugueses de Moçambique tendo ficado apenas os instrutores António Prista, Humberto Coimbra (falecido), Abdul Abdula, Martinho Fernandes, Camilo Antão, Fátima Binasse, Margarida Abranches, Rui Tadeu, Jonas Xerindza, José Pereira, Pio Matos e Joel Libombo. Apesar de alguns destes ainda não possuírem o diploma de conclusão do curso foram colocados para lecionarem aulas em diferentes escolas.

Esta situação fez com que o governo de Moçambique adotasse medidas para solucionar o problema da falta de professores no sistema de ensino. Neste contexto, foram mobilizadas e recrutadas pessoas (estudantes que estavam nas classes superiores) que tinham habilitações mínimas, mesmo sem formação, para assegurarem o processo de ensino.

Para Muria (2009), os novos professores, sem nenhuma formação, asseguravam o processo conforme as suas experiências colhidas como alunos na sala de aula. Todavia, esta situação não deixava o Governo tranquilo dado que os modos de ensinar dos novos professores estavam profundamente influenciados pelos seus professores que por sinal estavam comprometidos com a ideologia colonial.

Em virtude desta situação, em 1976, foi reaberta a Escola de Educação Física de Maputo (Ex- Escola de Instrutores de Educação Física de Lourenço Marques) e, em 1977, a Escola de Educação Física de Quelimane para formar professores e quadros de Educação Física e Desporto. Nos primeiros anos foram formados professores com o nível básico onde os candidatos ingressavam com a $6^{\text {a }}$ classe e tinham uma formação que durava entre 6 a 12 meses. Salienta-se que os formandos eram selecionados nas escolas segundo o perfil que respondia à disciplina que iria ensinar, ou seja, os melhores alunos de uma determinada disciplina eram recrutados para serem formados nessa disciplina. Contudo, esta ação criou descontentamento no seio dos jovens porque muitos não queriam seguir a carreira de professor.

A formação de professores teria como ação prioritária ter um caráter profundamente ideológico que conferisse ao professor a consciência da classe capaz de educar o aluno nos princípios do marxismo-leninismo (MOÇAMBIQUE, 1983). Na argumentação de Muria (2009), a formação de professores após a independência foi influenciada por medidas políticas e sociais que terão orientado a construção destes cursos no país, pois, a educação passa a ser o instrumento principal para a criação do Homem Novo, idealizado como o produto da realidade objetiva e da transformação subjetiva, devendo romper e libertar-se de valores e de toda a carga ideológica e política da formação colonial e/ou tradicional.

Neste âmbito, foram realizados 5 tipos de cursos para a formação de professores de Educação Física e Desporto de nível médio, nomeadamente: $6^{\mathrm{a}}+1,6^{\mathrm{a}}+5,9^{\mathrm{a}}+3 / 10^{\mathrm{a}}+2$, 9+18 meses $^{5}$, no período de 1975 a 2003. Estes visavam responder às necessidades imediatas do país em função do período histórico que foram implementados, daí optarmos por descrever cada curso.

O curso $6^{\mathrm{a}}+1$ decorreu de 1976 a 1978 e visava a formação de professores para todos os níveis e subsistemas do SNE. O nível de ingresso era a $6^{\text {a }}$ classe e tinha a duração de um ano. A prática desse programa era formar em curto espaço de tempo professores que assegurariam a lecionação de Educação Física nos subsistemas de Ensino Geral, Ensino Técnico Profissional, Formação de Professores e Ensino Superior (IMPULSO, 1987).

\footnotetext{
${ }^{5}$ Curso de equiparação destinado aos professores formados no modelo $6^{\mathrm{a}}+1$.
} 
Muria (2009), ao analisar a concepção epistemológica do curso, observou que obedecia à orientação tradicional com o objetivo de formar especialistas na execução de tarefas. Os conteúdos do desporto, com equivalência de disciplinas, visavam formar especialista que tinham que saber fazer, garantido pelas modalidades de Atletismo, Basquetebol, Futebol, Ginástica, Handebol, Natação e Voleibol (disciplinas da área das práticas da especialidade) e saber estar, que era garantido pelas disciplinas de Educação Política, Sociologia, História de Educação Física (área de política ideológica).

Entre 1979 e 1982 foi introduzido o curso $6^{a}+5$ que para além das disciplinas do curso anterior, era lecionado disciplinas do ensino geral (Língua Estrangeira, Português, Matemática, Química, Física, Estatística, Geografia, História) de modo a conferir o nível médio (12 $2^{\mathrm{a}}$ classe). Neste curso foram acrescentadas outras áreas de saber nomeadamente: Área Pedagógica (Psicologia, Pedagogia, Teoria de Educação Física, Teoria de Treino, Biologia Metodológica, Estágio Pedagógico), Área dos Fundamentos da Especialidade (História e Sociologia, Biomecânica, Biologia, Estatística, Avaliação das Qualidades Físicas) e Área das Atividades Complementares (Práticas Docentes e Estágio) (TEMBE, 2005).

Como afiança Muria (2009), a área geral, representava os conteúdos de saberes transitórios que não estavam diretamente ligados à vida profissional do futuro professor, mas serviam de base para prosseguir os estudos no nível superior. Outrossim, este curso, fornecia competências para os futuros professores lecionarem paralelamente a disciplina de Biologia como solução à falta de docentes. Neste contexto, a planificação do curso por áreas de saber, poderia constituir uma base para a formação integral dos professores, se, se observasse o carácter multidimensional e transdisciplinar que deve caracterizar a formação profissional na Educação Física e Desporto.

A partir de 1983, o nível de ingresso passou a ser $9^{a}$ classe e a duração reduziu para três anos $\left(9^{a}+3^{6}\right)$ o que correspondia ao nível médio. O programa de formação alterou ligeiramente, com a introdução de novas disciplinas como: Organização e Planificação, Primeiros Socorros, Medicina Desportiva e Sensibilização às Modalidades $^{7}$ e Trabalho de Conclusão (TEMBE, 2005). Paralelamente ao curso $9^{\mathrm{a}}+3$, em 1987, foi criado o curso de equiparação para os professores que tinham realizado o curso $6^{\mathrm{a}}+1$. Ao concluírem a $9^{\mathrm{a}}$ Classe, frequentavam o curso durante 18 meses e no final era outorgado o nível médio.

Olhando para este curso as maiores dificuldades que os formandos tinham derivavam das características das suas zonas de origem onde muitas das vezes não tinham campos para a prática de modalidades de salão o que se tornava um obstáculo à sua formação. Para colmatar esta lacuna, estes formandos tinham que usar os seus tempos livres para treinar as modalidades que tinham mais dificuldade com o apoio dos mais experientes. Um dos autores deste artigo teve a sua formação inicial neste curso $9^{\mathrm{a}}+3$.

Para além da formação de professores no país, a partir da década de 1980, outros moçambicanos que tinham concluído os cursos $6^{\mathrm{a}}+5$ ou $9^{\mathrm{a}}+3$ foram enviados ao exterior para formação superior em Educação Física, especialmente em países do leste: URSS, Hungria, República Democrática da Alemanha, Bulgária, Tchecoslováquia e Cuba,

\footnotetext{
${ }^{6}$ Mais tarde, em 2002, passou a designar-se $10^{\mathrm{a}}+3$. O curso foi extinto em 2003 pelo Diploma Ministerial 64/2003 (MOÇAMBIQUE, 2003).

${ }^{7}$ Nos primeiros cursos e mesmo até agora, os estudantes vindos de várias regiões não traziam consigo o repertório motor específico para a prática de várias modalidades desportivas, assim, o curso tomou a decisão de montar um programa de demonstração e prática fora das horas normais destas modalidades. Geralmente, os estudantes que são admitidos na Faculdade, às vezes, nem conhecem um campo (quadra) de basquetebol e nem a respectiva bola (MURIA, 2009).
} 
através dos acordos de cooperação assinados com estes países. Um dos autores do artigo, inclusive, beneficiou-se de uma bolsa para frequentar o curso superior em Cuba.

A partir de 1993, inicia-se o curso superior para formação de professores no Instituto Superior Pedagógico ${ }^{8}$, através da criação da Faculdade de Ciências de Educação Física e Desporto (FCEFD), como forma de dar novo impulso à área de Educação Física e Desporto no país. Participaram da constituição da faculdade os professores Manuel Morais ( $1^{\circ}$ Diretor da Faculdade), Ângelo José Muria e Ilídio da Silva, assessorados por Peter Bancov de nacionalidade Búlgara.

A formação de professores na FCEFD acontecia em dois níveis, Bacharelato (3 anos) e Licenciatura (2 anos) e estes deviam estar habilitados a trabalharem na Educação Geral, Formação de Professores e Educação Superior.

O bacharelato correspondia aos 3 primeiros anos do curso e o candidato era graduado e poderia, se o quisesse, ir ao mercado de trabalho ou optar por continuar com os estudos para concluir a licenciatura ao frequentar os últimos 2 anos. Os professores que garantiram o funcionamento inicial deste curso foram os que fizeram parte do primeiro grupo formado nos países do leste.

O curso apresentava como objetivo geral formar professores e quadros da educação de nível superior com conhecimentos científicos adequados e domínio das técnicas especiais, isto é, que possuam alto nível de competência e qualidade científica, técnica, pedagógica, didática e profissional e que sejam capazes de exercer uma cidadania ativa e responsável, na defesa da dignidade e respeito pelos direitos humanos, na promoção do bem de todos, sem discriminação e na construção de uma sociedade mais livre, justa e democrática (UP, 1995).

Como nos explica Muria (2009), na constituição curricular dos cursos de formação de professores de Educação Física e Desporto em Moçambique, o conhecimento disciplinar apareceu historicamente como um todo, mas ele não foi desenvolvido dessa forma.

No curso de bacharelato e licenciatura em Educação Física e Desporto, os conteúdos do desporto foram agrupados numa disciplina denominada Estudos Práticos. No primeiro ano (Estudos Práticos I) eram lecionadas as modalidades de Handebol, Ginástica e Natação e no segundo ano (Estudos Práticos II), eram ministradas as modalidades de Atletismo, Basquetebol, Futebol e Voleibol.

Muria (2009) constata que a organização da disciplina de Estudos Práticos visava o tratamento dos conteúdos de forma unificada, mas a sua operacionalização não conseguiu evitar a fragmentação. No entanto, o mesmo autor considera que a fragmentação disciplinar pode ter trazido algumas vantagens pelo fato de ter possibilitado a organização das diversas áreas de conhecimento graças à redução. Ao mesmo tempo, assistiu-se a um crescente conformismo sobre a importância da área de conhecimento (práticas de especialidade), para uma formação integral do estudante.

De uma estrutura que se pretendia interdisciplinar passou a disciplinar, como fundamenta Zabala (2002, p.33), “[...] a organização de conteúdos ficou mais tradicional, onde os conteúdos escolares apresentam-se por matérias independentes umas das outras". As disciplinas são propostas simultaneamente sem que se manifestem explicitamente as relações que possam existir entre elas.

Desta forma, o curso deixou de formar professores capazes de participar no processo de elaboração de novas ideias e conceitos, tão fundamentais para o exercício da cidadania crítica, prática, reflexiva e a participação na sociedade moçambicana, de onde tanto se valoriza o conhecimento (MURIA, 2009).

\footnotetext{
${ }^{8}$ Em 1995 passa a ser Universidade Pedagógica.
} 
Para Morin (2009), não há uma articulação entre os saberes separados, fragmentados, compartimentados entre disciplinas e as realidades, problemas cada vez mais pluridisciplinares, transversais, multidimensionais, transnacionais, globais, planetários. Por isso, a excessiva especialização impede de ver o global bem como o essencial. A divisão das disciplinas no ensino dificulta apreender o que é construído junto.

No nosso entender, a formação de professores de Educação Física tem sido estruturada de forma dissociada porque as matérias de ensinos são tratadas de forma fragmentada. Por exemplo, as várias modalidades que constituem temas da disciplina de Educação Física são tratadas como disciplinas que visam à eficiência e o rendimento do aluno, não olhando para a transversalidade e a interligação desses conteúdos para constituir um todo.

É na tentativa de articular os saberes que, em $2004^{9}$, o curso de formação de professores de Educação Física e Desporto passou por mudanças: de 5 para 4 anos; introdução do modelo integrado nas práticas pedagógicas. A concepção das práticas pedagógicas num sistema curricular integrado de formação de professores funda-se numa Epistemologia da Prática em que os conhecimentos dos futuros professores resultam de prática vivida e experimentada na escola (DIAS et al., 2010). Os estudantes a partir do $1^{\circ}$ ano de formação começam a ter contato com o futuro local de trabalho (escola) onde vão lidar com situações de ensino, a partir do $2^{\circ}$ ano.

Em 2009, ocorre a terceira reforma curricular da UP na qual são introduzidas áreas de concentração. Segundo o artigo 44 das Bases e Diretrizes Curriculares, para que os graduados estejam habilitados a trabalhar em mais de uma área profissional, os cursos da UP devem ter currículos organizados em áreas de concentração maiores (major) ou menores (minor). Assim, cada curso deveria planificar mais de uma saída profissional para os seus graduados (UP, 2008).

O curso de formação de professores de Educação Física e Desporto introduziu como outras saídas profissionais: o Treinamento de Crianças e Jovens; o Desporto e Saúde. Ou seja, o candidato se forma como professor de Educação Física e tem uma formação opcional que pode ser numa das duas áreas. Estas transformações curriculares resultaram da análise do mercado de trabalho na qual se verificou que ser treinador desportivo, gestor desportivo ou monitor de academia não eram profissões com enquadramento legal no país, o que significaria formar pessoas para o desemprego. É neste sentido que se optou por transformar essas áreas de formação em minor. Neste sentido, o curso passa a ter como objetivo formar professores com conhecimentos científicos e competências para ensinar Educação Física e Desporto, habilitados em Treino Desportivo para Crianças e Jovens ou Desporto e Saúde - academias, fitness e centros de reabilitação física (UP, 2009).

Este curso foi revisto em 2013 com as seguintes alterações: (1) O minor Desporto e Saúde passa a designar-se Atividade Física e Saúde; (2) Introdução do terceiro minor centrado na Habilitação em Gestão do Desporto; (3) A cadeira de Teoria do Treino Desportivo passa a ser de tronco comum para a formação de professores de Educação Física e adota a denominação precisa de Teoria e Metodologia do Treino Desportivo; (4) O fracionamento da cadeira de Crescimento e Nutrição em duas separadas; (5) Introdução da disciplina de Empreendedorismo e Inovação no Desporto (UP, 2014).

No entanto, os cursos superiores em Educação Física e Desporto conheceram um novo impulso com a introdução do curso de Mestrado em Educação Física e Desporto, em 2008, Mestrado em Treino de Crianças e Jovens (2009), Mestrado em Atividade

\footnotetext{
${ }^{9}$ Em 2003 inicia a segunda reforma curricular da Universidade Pedagógica (UP).
} 
Física e Saúde (2011) e Mestrado em Gestão do Desporto (2017). Em 2015 introduz-se o curso de doutorado em Ciência do Desporto com especialidade em Treinamento Desportivo e gradualmente serão introduzidas outras especialidades.

Além dos cursos superiores importa referir que foi criado em 2017 o Instituto Médio de Desporto e Educação Física de Moçambique que visa formar professores de Educação Física e profissionais do Desporto do nível médio. Esta iniciativa é o recomeço da formação de professores de Educação Física com o nível médio extinto em 2003.

\section{ATUAÇÃo PROFISSIONAL EM EdUCAÇÃO FíSICA E DESPORTO}

Os profissionais que atuavam no sistema educativo no período colonial eram militares que estavam em missão de serviço. Por isso, a prioridade era ministrar as aulas de Educação Física nas escolas oficiais, uma vez que os professores da especialidade eram insuficientes para todo o sistema de educação. Este cenário fez com que as autoridades portuguesas se preocupassem com a lecionação das aulas para as outras escolas (DOMINGOS, 2006).

A preocupação do poder colonial com o fraco impacto da Educação Física sobre os praticantes pode-se verificar no preâmbulo do diploma 1670, citado por Muria (2009), no qual se destaca que:

\footnotetext{
[...] o interesse do estado é o desenvolvimento da Educação Física do povo português e esta há de fazer-se, antes de tudo, através de métodos de ginástica adequados a serem executados em escolas, permitindo, assim, a vigilância permanente sobre os executantes e a gradação conveniente dos exercícios (p. 201).
}

Observa-se que a ginástica praticada só com o intuito de formação física não exerce, ainda, sobre a população, a atração desejável, o mesmo não acontecendo com os desportos. Assim, recomendava-se a assistência e a vigilância médica dos praticantes em todas as idades. Apesar de o diploma reconhecer o sentido e o interesse nacional e social das práticas desportivas, ele recomendava que relevância especial fosse dada às competições desportivas. A prática de Educação Física também teve a sua existência e o seu desenvolvimento nos diferentes órgãos de orientação e fiscalização da Educação Física e Desportos (CRISTÓVÃO, 2005).

A Educação Física foi desenvolvida pela instituição militar como sustentáculo de uma visão nacionalista do corpo. Desde a primeira metade do século XIX, que as companhias do exército organizavam exercícios físicos. Do universo militar, a Educação Física militarizada, passou para o sistema escolar. O Liceu 5 de Outubro, no início do século XX, inaugurou em Lourenço Marques a instrução da disciplina através de metodologias científicas (DOMINGOS, 2006).

A ginástica sueca, ou método de Ling, era o exemplo paradigmático da abordagem científica da disciplina, por oferecer mais garantias de ser um método racional e psicológico, aplicável tanto a civis como a militares, e que atinge os objetivos essenciais, físicos e morais (DOMINGOS, 2006).

Outras atividades físicas existentes em Moçambique foram também cultivadas no contexto militar, nomeadamente: desportos de combate, tiro e esgrima, desportos atléticos, como os saltos, as corridas, os lançamentos, o pentatlo, o hipismo, a natação e os desportos equestres (DOMINGOS, 2006). 
ATUAÇ̃̃o Profissional EM EdUCAÇão FísICA E DESPORTO APÓS A INDEPENDÊnCIA

A atuação dos professores de Educação Física após a independência de Moçambique passou a abranger o Ensino Primário e o Ensino Secundário. O ensino Primário ${ }^{10}$ divide-se em três ciclos de aprendizagens nomeadamente $1^{\circ}\left(1^{\mathrm{a}}\right.$ e $2^{\mathrm{a}}$ classes $)$, $2^{\circ}\left(3^{\mathrm{a}}, 4^{\mathrm{a}}\right.$ e $5^{\mathrm{a}}$ classes $)$ e $3^{\circ}\left(6^{\mathrm{a}}\right.$ e $7^{\mathrm{a}}$ classes $)$. Por sua vez, o Ensino Secundário divide- se em 2 ciclos de aprendizagens: $1^{\circ}\left(8^{\mathrm{a}}\right.$ a $10^{\mathrm{a}}$ classe $)$ e $2^{\mathrm{o}}\left(11^{\mathrm{a}}\right.$ e $12^{\mathrm{a}}$ classes $)$ (MOÇAMBIQUE, 1992).

No período entre 1975 e 2003, a Educação Física era pouco praticada nas escolas moçambicanas. Razões como programas desajustados à realidade moçambicana, saída de muitos professores de Educação Física com formação logo depois da independência, formação deficiente dos professores, aulas de Educação Física ministrada por não formados, ausência de manuais escolares para professores e escassez de espaços físicos e infraestruturas adequadas para a sua prática ditaram o fracasso desta disciplina em algumas escolas (MURIA; PICARDO; PESSULA, 2006).

Também o número excessivo de alunos por turma, entre 70 e 90 no Ensino Primário e entre 40 e 50 no Ensino Secundário, aliado ao facto de, na mesma sala de aula, estarem presentes falantes de diferentes línguas, de um total de 22 línguas do país, por vezes se encontram até 4 línguas, dificultando comunicação entre docente e estudantes, constituem outro entrave na lecionação.

O programa de Educação Física do ensino primário e secundário que vigorou no período de 1930 a 2003 não sofreu nenhuma alteração nem ajustamento ao nível dos temas, atualidade científica e metodológica, mesmo depois da evolução, a nível mundial, das modalidades em termos de regulamentação. Os temas de Educação Física eram constituídos por Atletismo, Basquetebol, Futebol, Ginástica, Handebol e Voleibol, o que demonstra predomínio de conteúdos hegemônicos e eurocêntricos na escola em detrimento de jogos e danças tradicionais moçambicanas.

No entanto, com as reformas curriculares de 2003 (ensino primário) e 2008 (ensino secundário) verificou-se a necessidade de atribuir $20 \%$ dos conteúdos lecionados ao Currículo Local ${ }^{11}$. Nesta perspectiva, as práticas étnico-culturais da comunidade tem espaço para serem lecionados a partir dos saberes que os pais, encarregados de educação e os líderes comunitários possuem.

Outra realidade da atuação profissional é que as poucas escolas que possuem espaços para a prática debatem-se com o problema da programação dado que na mesma hora estão programadas mais de quatro turmas para terem aulas de Educação Física.

Um estudo realizado pelo INDE/MEC (2005) no ensino secundário constatou que muitos alunos responderam negativamente à preferência da disciplina de Educação Física comparativamente a outras disciplinas do currículo. Apurou-se igualmente, em uma pequena amostra da atuação profissional, que dos 46 professores de Educação Física inquiridos, 22 não tinham formação na área, 21 tinham o nível médio e 2 licenciatura.

Outrossim, o Ministério da Educação e Cultura em parceria com o UNICEF realizou uma pesquisa para verificar quais os conhecimentos, práticas e atitudes dos professores que atuam no ensino primário e secundário em Educação Física nas províncias de Gaza, Sofala, Zambézia, Nampula e Cabo Delgado. Do estudo, constatouse que: (1) os entrevistados reconhecem a importância da Educação Física e Desporto na promoção da saúde, na formação integral da criança e na aprendizagem de outros

\footnotetext{
${ }^{10}$ As crianças ingressam na escola primária com 6 anos de idade.

${ }^{11}$ O Currículo Local é uma componente do currículo nacional correspondente a $20 \%$ do total do tempo previsto para a lecionação de cada Disciplina. Esta componente é constituída por conteúdos definidos localmente como sendo relevantes, para a integração da criança na sua comunidade (INDE/MEC, 2003).
} 
conhecimentos; (2) a sua implementação está sujeita a constrangimentos de ordem material, infraestrutural, capacitação de professores; (3) os professores privilegiam o ensino das técnicas em prejuízo das razões pelas quais são ensinadas, o jogo; (4) a dança e jogos tradicionais não são devidamente lecionados no ensino secundário; (5) há interferência de questões étnico-culturais na participação das meninas ${ }^{12}$ nas aulas (MEC, 2009).

A atuação profissional é igualmente influenciada pelo fator cultural de divisão de papéis nas zonas rurais, como nos elucida Castiano (2008, p. 8):

\begin{abstract}
Os rapazes ainda cedo são educados a ter destreza e força para poder trepar árvores para tirar frutas, poder resistir à dor, [...] por isso, devem ser bravos e fortes. Cedo são lhes exigido habilidades, não só cognitivas, mas também de domínio corporal como construir uma casa, cuidar de um rebanho, correr para transmitir notícias a famílias longínquas, saber nadar, pescar e caçar. Por outro lado, as raparigas devem aprender a conhecer o seu corpo, a saber aguentar com prazer a dor da gravidez, a não serem preguiçosas porque devem trazer água, acordar muito cedo para varrer o quintal, cuidar dos irmãos mais novos, conter-se dos excessos que a vida dispõe.
\end{abstract}

Constatamos que nas zonas urbanas as preocupações com o corpo estão relacionadas com a obesidade devido à crescente urbanização. Por isso, a Educação Física apresenta uma ideia de manutenção da saúde e a aquisição da aptidão física entre outras finalidades como atesta o artigo de Saranga, Prista e Maia (2002), que demonstra existir uma tendência de diminuir a aptidão física devido à alteração do estilo de vida das crianças e jovens provocadas pela falta de espaço para a realização das atividades físicas, jogos, brincadeiras e pela proliferação dos jogos eletrônicos.

Daí entendermos que o ensino da Educação Física nas zonas rurais e urbanas está submetido à educação de valores, isto é, educar o corpo significa fortalecê-lo para superar os desafios da vida ou moldá-lo para ser perfeito. Isto mostra que a atual Educação Física apresenta fortes marcas do paradigma cartesiano, que fragmenta e mecaniza o corpo, quando pretende educar o corpo para suportar a dor, sobreviver, ser ativo e esbelto.

Olhando para os propósitos do Governo verificamos que a área de Educação deve assegurar que cada criança na escola tenha conhecimentos e habilidades básicas que lhe permitam saber ler, escrever e contar. Por outro, apresenta como prioridades do Governo para a área do Desporto garantir a prática regular da atividade física e desportiva em todos os subsistemas desportivos contribuindo para que os jovens desenvolvam o capital humano e social (MOÇAMBIQUE, 2015).

Todavia, podemos observar neste documento a convivência entre o corpo-objeto e o corpo-sujeito quando, por um lado prioriza-se o desenvolvimento da mente na escola (saber ler, escrever e contar) e, por outro lado, preocupa-se em desenvolver o capital humano e social ${ }^{13}$ através do desporto, fora da escola.

Entre 2012 e 2017, em visitas às escolas primárias nas cidades de Maputo, Matola e Tete nas quais pretendíamos observar a lecionação da Educação Física verificamos a atuação deficitária do professor de Educação Física no $1^{\circ}$ e $2^{\circ}$ ciclos do ensino primário, pois, estes enfrentam dificuldades didático-metodológicas para ensinar os temas

\footnotetext{
${ }^{12} \mathrm{O}$ uso de calções não é bem vista pelos mais velhos.

${ }^{13} \mathrm{O}$ capital humano e social é um conjunto de capacidades, conhecimentos, competências e atributos de personalidade individual e coletiva que favorecem a realização de atividades sociais e econômicas necessárias para o desenvolvimento socioeconômico sustentável e integrado do País (MOÇAMBIQUE, 2015).
} 
programados e algumas vezes não lecionam as aulas nestas classes alegando motivos como a escassez de instalações e materiais.

No entanto, os professores que leccionam os seus temas nas aulas de Educação Física são forçados a buscar estratégias como nos apresenta Pessula (2014), a partir da realidade da Cidade da Matola, a qual nos permite elucidar a atuação do professor aonde verificamos o uso de espaços existentes no pátio escolar para criar condições de práticas com características que se ajustam ao tipo de aula, sendo o atletismo, ginástica, futebol, basquetebol, handebol e voleibol os temas lecionados. Simultaneamente há a produção de materiais alternativos de baixo custo como, por exemplo, paus de vassouras cortadas a tamanho de $20 \mathrm{~cm}$ para servir de testemunhos no atletismo; capulana ${ }^{14}$. para servir de tapete na ginástica; cordas para servir de rede no voleibol.

Em escolas observadas na cidade de Tete foi possível verificar que os professores assumem a desconstrução de gênero nos seus discursos, porém, na prática não acontece. Observamos na organização e orientação das aulas (prática) a separação de atividades por gênero associada às características biológicas (BIVE; PESSULA, 2018).

\section{CONSIDERAÇõeS}

Consideramos que desde o período colonial até hoje a formação de professores sofreu várias metamorfoses em função da realidade de cada época (colonial e pósindependência), mas continuam os desafios para que a mesma atenda à realidade atual da escola como local da liberdade, da solidariedade e da valorização das diferenças e construção de identidades.

Apuramos que não houve mudanças em conteúdos lecionados na Educação Física escolar continuando os mesmos que eram leccionados no período colonial, ou seja, Atletismo, Basquetebol, Futebol, Handebol, Ginástica e Voleibol; embora tenham sido introduzidos os jogos e danças tradicionais.

A atuação profissional dos professores continua sendo influenciada pelos preconceitos e estereótipos de gênero e corpo onde se verifica a separação de meninos e meninas nas aulas e no tipo de atividade desportiva a realizar na aula em função do corpo. Por outro lado, há influências das práticas sociais e culturais como os mitos e tabus nas aulas: às alunas não são permitidas pôr calções por se considerar falta de respeito aos mais velhos.

Em função destas constatações, perspectivamos reconstruir a formação e a atuação profissional do professor de Educação Física a partir de um olhar intercultural e póscolonial das práticas e saberes nas aulas das nossas escolas. Daí que colocamos alguns desafios:

(1) Como lidar com o corpo - sujeito do aluno valorizando as diferenças culturais nas nossas escolas num país multiétnico e linguístico?

(2) Como usar o rico patrimônio de atividades lúdicas e culturais que as crianças desenvolvem no seu dia-a-dia nos intervalos e nas zonas residenciais nas aulas de Educação Física de modo a formar um corpo sujeito concebido como situado no mundo (MERLEAU- PONTY, 2006), valorizando as vivências educativas dos sujeitos, substituindo a transmissão para pelo educar com (FREIRE, 2011).

(3) Como transformar as práticas pedagógicas dos professores na lecionação da Educação Física numa perspectiva intercultural e descolonial/pós-colonial?

\footnotetext{
${ }^{14}$ Tecido que as mulheres utilizam para amarrar na cintura como vestimenta no lugar da saia.
} 


\section{REFERÊNCIAS}

BIVE, M.; PESSULA, P. Percepções sobre as relações de gênero em escolas de Moçambique- discurso e pratica. Motricidades, v. 2, n. 3, p. 201-209, set.-dez. 2018.

CASTIANO, J. Vigilância epistemológica: um olhar glocal sobre as ciências filosofia e educação física (I). Jornal UP Noticias, v. 1, n. 1, p. 8-9, dez. 2008.

CONNELLY, F. M.; CLANDININ, J. Stories of experience and narrative inquiry. Educational Researcher, v. 19, n. 5, p. 2-14, 1990.

CRISTÓVÃO, F. Lusofonia: dicionário temático da lusofonia. In: CRISTÓVÃO, F. A., AMORIM, M. A., MARQUES, M. L. G.; MOITA, S. B. Dicionário temático da lusofonia. Lisboa: Texto Editores, 2005. p. 652-656.

DIAS, H.; SANTOS, N.; CRUZ, P.; GOMANE, O.; GUIMINO JÚNIOR, E.; SIMÃO, J. Manual de Práticas e Estágio Pedagógico. 2. Ed. Maputo: Educar-UP, 2010.

DOMINGOS, N. Futebol e colonialismo, dominação e apropriação: sobre o caso moçambicano. Análise Social, v. 41, n. 179, p. 397-416, 2006.

FREIRE, P. Pedagogia da esperança: um reencontro com a pedagogia do oprimido. Rio de Janeiro: Paz e Terra, 2011.

IMPULSO. Secretaria de Estado de Educação Física e Desportos. Revista de Educação Física e Desportos de Moçambique, n. 1, 1987.

INDE/MEC. Instituto Nacional do Desenvolvimento da Educação. Ministério da Educação e Cultura. Relatório do Diagnóstico do Ensino Secundário Geral. Maputo: INDE/MEC, 2005.

INDE/MEC. Instituto Nacional do Desenvolvimento da Educação. Ministério da Educação e Cultura. Plano Curricular do Ensino Primário: Objetivos, política, estrutura, plano de estudos e estratégias de implementação. Maputo: INDE/MEC, 2003.

INE. Instituto Nacional de Estatística- Moçambique. Anuário Estatístico. Maputo: INE, 2017.

MEC. Ministério de Educação e Cultura. Conhecimentos, Atitudes e Práticas em Educação Física e Desporto nas escolas primárias e secundárias de Moçambique. Relatório de pesquisa. Maputo: MEC, 2009.

MERLEAU-PONTY, M. Fenomenologia da percepção. 3. ed. São Paulo: Martins Fontes, 2006.

MOÇAMBIQUE, R. Programa Quinquenal do Governo para 2015-2019. Maputo: Imprensa Nacional, 2015.

MOÇAMBIQUE, R. Diploma Ministerial 64/2003 de 18 de junho. Maputo: Imprensa Nacional, 2003.

MOÇAMBIQUE, R. Política Nacional da Educação. BR n. 41 de 11 de Outubro de 1995. Maputo: Imprensa Nacional, 1995.

MOÇAMBIQUE, R. Lei no. 6/92 - Sistema Nacional de Educação. Boletim da República: Publicação Oficial da República de Moçambique. Maputo: Imprensa Nacional, 1992.

MOÇAMBIQUE, R. Lei no. 4/83 - Sistema Nacional de Educação. Boletim da República: Publicação Oficial da República de Moçambique. Maputo: Imprensa Nacional, 1983.

MORIN, E. A cabeça bem-feita: repensar a reforma, reformar o pensamento. 16. ed. Rio de Janeiro: Bertrand Brasil, 2009. 
MURIA, A. A complexidade da formação de professores: o caso da educação física e desporto em Moçambique. 2009. Tese (Doutorado em Educação) - Faculdade de Ciências Humanas, Universidade Metodista de Piracicaba, Piracicaba, 2009.

MURIA, A.; PICARDO, S.; PESSULA, P. Políticas e as práticas da educação física e desporto em Moçambique. Relatório de pesquisa. Maputo: UNESCO, 2006.

PESSULA, P. Ensino de educação física no ensino básico em Moçambique com uso de meios alternativos. Revista Portuguesa de Ciências do Desporto (RPCD), Faculdade de Desporto da Universidade do Porto, n. 1, p. 872-888, 2014.

SARANGA, S.; PRISTA, A.; MAIA, J. Mudança nos níveis de aptidão física em função de alterações políticas e socioeconômicas de 1992-1999. In: PRISTA, A.; MAIA, J.; SARANGA, S.; MARQUES, A. (Ed.). Saúde, crescimento e desenvolvimento: um estudo epidemiológico em crianças e jovens de Moçambique. Maputo: Multitema, 2002. p. 71-87.

TEMBE, V. A. Estudo intercultural dos fatores da motivação para a prática das atividades desportivas - Caso de Jovens moçambicanos em idade escolar. 2005. Tese (Doutorado em Ciências Humanas e Sociais - Ciências de Desporto/Psicologia do Desporto) - Universidade de Trás-os-Montes e Alto Douro, Vila Real, 2005.

UP. Universidade Pedagógica. Plano Curricular do Curso de Licenciatura em Ensino de Educação Física e Desporto. Maputo: UP/FEFD, 2014.

UP. Universidade Pedagógica. Plano Curricular do Curso de Licenciatura em Ensino de Educação Física e Desporto. Maputo: UP/FEFD, 2009.

UP. Universidade Pedagógica. Centro de Estudos e Políticas Educativas (CEPE). Bases e Diretrizes Curriculares para os cursos de Graduação da Universidade Pedagógica. Maputo: UP/CEPE, 2008.

UP. Universidade Pedagógica. Anuário 1995-1996. Maputo: Universidade Pedagógica, 1995.

ZABALA, A. Enfoque globalizador e pensamento complexo. Porto Alegre: Artmed, 2002.

Recebido em: 26 jan. 2019.

Aprovado em: 06 mar. 2019. 